\title{
A non-lethal technique for detecting the chytrid fungus Batrachochytrium dendrobatidis on tadpoles
}

\author{
Richard W. R. Retallick ${ }^{1,3, *}$, Verma Miera ${ }^{1}$, Kathryn L. Richards ${ }^{1,4}$, \\ Kimberleigh J. Field ${ }^{2,5}$, James P. Collins ${ }^{1}$ \\ ${ }^{1}$ School of Life Sciences, Arizona State University, PO Box 874501, Tempe, Arizona 85287-4501, USA \\ ${ }^{2}$ Arizona Game and Fish Department, 2221 W. Greenway Rd., Phoenix, Arizona 85023-4399, USA \\ ${ }^{3}$ Present address: 1 Walter Street, South Yarra, Victoria 3141, Australia \\ ${ }^{4}$ Present address: Yale University, School of Forestry \& Environmental Studies, 370 Prospect St., New Haven, \\ Connecticut 06511, USA \\ ${ }^{5}$ Present address: U.S. Fish and Wildlife Service, 1340 Financial Blvd. \#234, Reno, Nevada 89502, USA
}

\begin{abstract}
Batrachochytrium dendrobatidis $(B d)$ infection on post-metamorphic frogs and salamanders is commonly diagnosed using polymerase chain reaction (PCR) of skin scrapings taken with mildly abrasive swabs. The technique is sensitive, non-lethal, and repeatable for live animals. Tadpoles are generally not sampled by swabbing but are usually killed and their mouthparts excised to test for the pathogen. We evaluated a technique for non-lethal $B d$ diagnosis using quantitative PCR (qPCR) on swabs scraped over the mouthparts of live tadpoles. The sensitivity of non-lethal (swabbing) and lethal (removal of mouthparts) sampling was assessed using $150 \mathrm{Bd}$-infected Rana subaquavocalis tadpoles. Swabbing was consistently less sensitive than lethal sampling, but still detected $B d$. Experimental $B d$ prevalence was $41.1 \%$ when estimated by destructively sampling mouthparts and 4.7 to $36.6 \%$ (mean $=21.4 \%$ ) when estimated with swabs. Detection rates from swabbing varied with investigator and time since infection. The likelihood of detecting $B d$-infected tadpoles was similar regardless of size and developmental stage. Swabbing mouthparts of live tadpoles is a feasible and effective survey technique for $B d$, but, because it is less sensitive, more tadpoles must be sampled to estimate prevalence at a confidence level comparable to destructive sampling.
\end{abstract}

KEY WORDS: Batrachochytrium dendrobatidis · Tadpole · Detection · PCR · Technique · Chytridiomycosis

Resale or republication not permitted without written consent of the publisher

\section{INTRODUCTION}

The amphibian chytrid fungus Batrachochytrium dendrobatidis $(B d)$ is pathogenic to amphibians (Berger et al. 1998) and linked to enigmatic amphibian declines (Stuart et al. 2004). Bd infects pre- and postmetamorphic amphibians, but mortality occurs only in post-metamorphic individuals (Berger et al. 1998, Marantelli et al. 2004); therefore, most Bd surveys sample metamorphosed frogs rather than tadpoles (Speare 2005). Many studies would benefit from sampling tadpoles, which are often easier to detect and capture because they are confined to aquatic habitats and are generally less ephemeral and cryptic than metamorphosed individuals. Also, studies that nondestructively assess infection in rare or endangered species, or that sample the same individual repeatedly regardless of life-history stage, can contribute greatly to our basic understanding and management of disease (Brunner et al. 2004).

Until recently, histology was the most reliable and widely used method for detecting $B d$ on amphibians (Berger et al. 1999). Frogs can be sampled non-lethally by removing and screening part of 1 or more digits. Tadpoles, however, generally become infected with $B d$ only on their mouthparts (Berger et al. 1998, Marantelli 
et al. 2004, Knapp \& Morgan 2006), and are killed for histological diagnosis. This limits studies of amphibian disease, particularly those that span life-history stages.

The polymerase chain reaction (PCR) is the basis for a highly sensitive, non-destructive diagnostic technique for sampling post-metamorphic amphibians. An animal's skin is scraped or swabbed lightly with a finely pointed, slightly abrasive object, such as a wooden toothpick or cotton surgical swab, to remove the outermost skin cells, which are then screened for Bd DNA using real-time Taqman PCR assays (Boyle et al. 2004). Researchers studying chytridiomycosis in amphibians have used the swabbing technique for about $4 \mathrm{yr}$, and it is a generally accepted protocol used by several laboratories (Briggs \& Vredenberg 2004, Livo 2004, Kriger et al. 2006). We evaluate the sensitivity and feasibility of swabbing tadpole mouthparts for $B d$ diagnosis as a non-lethal alternative to histology. The project arose from a desire to learn more about the rare Ramsey Canyon leopard frog Rana subaquavocalis in southeastern Arizona, where $B d$ has been detected at several sites and tadpoles often remain at sites after frogs have become scarce or absent (K. J. Field pers. obs.). Wildlife managers are rightly reluctant to test for $B d$ by killing large numbers of tadpoles in small, vulnerable populations. Our question was: Could we detect $B d$ reliably and non-lethally in tadpoles using quantitative PCR?

\section{MATERIALS AND METHODS}

We collected 200 Rana subaquavocalis tadpoles (range of body lengths: 11.4 to $20.7 \mathrm{~mm}$ ) from Beatty's Guest Ranch in the Huachuca Mountains of Cochise County, Arizona, on 1 April 2005. Frogs and tadpoles are abundant and $B d$ has not been detected at this site. The tadpoles were taken to Arizona State University in Tempe Arizona for the duration of the experiment. Each tadpole was kept in a Ziploc (SC Johnson) 21/2 cup $(\sim 600 \mathrm{ml})$ square plastic container, with about $400 \mathrm{ml}$ of aged tap water and fed blanched and frozen endive lettuce with occasional supplements of dried fish food flakes. We checked tadpoles daily and refreshed their containers, water, and food weekly.

On 15 April and again on 19 April 2005 we inoculated 150 tadpoles with cultured $B d$ zoospores. Each tadpole was exposed to $5 \times 10^{5}$ zoospores over the 2 inoculations. This exposure level consistently infects susceptible species such as Ambystoma tigrinum and Pseudacris triseriata (V. Miera \& R. W. R. Retallick unpubl. data). For the first inoculation $3.5 \times 10^{5}$ zoospores were added to $250 \mathrm{ml}$ aged tap water for an effective exposure concentration of 140 zoospores $\mathrm{ml}^{-1}$ per tadpole. Four days later we moved all tadpoles to clean containers with $250 \mathrm{ml}$ fresh water and added the second inoculation of $1.5 \times 10^{5}$ zoospores to each container (effective exposure concentration of 64 zoospores $\mathrm{ml}^{-1}$ per tadpole). We simultaneously infected 10 postmetamorphic tiger salamanders Ambystoma tigrinum with the same doses of the same $B d$ cultures as a positive control to demonstrate that the $B d$ inoculations used on tadpoles could infect amphibians. Tiger salamanders easily become infected with $B d$ and then slough large amounts of infected skin cells that are well suited for $B d$ diagnosis (V. Miera \& R. W. R. Retallick unpubl. data). The remaining 50 tadpoles were negative controls, not exposed to $B d$.

There is increasing evidence that $B d$ isolates vary in their effects on host populations (Berger et al. 2005). Ideally, therefore, we should have inoculated tadpoles with $B d$ isolated from Rana subaquavocalis to maximize the chances of infection. Because no such isolate exists, we used $B d$ Strain 230 isolated by Joyce E. Longcore from Rana yavapaiensis collected in Montrose Canyon in southeastern Arizona, $125 \mathrm{~km}$ from Beatty's Guest Ranch. For our experiments the source of the strain was not important as long as experimental animals became infected, and they did.

The $B d$ culture was maintained in a TGHL broth (16 $\mathrm{g}$ tryptone, $4 \mathrm{~g}$ gelatin hydrolysate, $2 \mathrm{~g}$ lactose, $10 \mathrm{~g}$ agar, and $1000 \mathrm{ml}$ distilled $\mathrm{H}_{2} \mathrm{O}$ ) in $25 \mathrm{~cm}^{3}$ tissue culture flasks at $10^{\circ} \mathrm{C}$ and passaged every few weeks under sterile conditions. For each passage, $2 \mathrm{ml}$ of broth was extracted from the active culture and added to $10 \mathrm{ml}$ of fresh TGHL in a new flask. To obtain zoospores for each inoculation, a freshly passed culture was left for $3 \mathrm{~d}$ at room temperature $\left(\sim 21^{\circ} \mathrm{C}\right)$ before all supernatant was removed, leaving only $B d$ sporangia attached to the walls of the empty flask. The desired volume of a dilute saline solution (DS) (Boyle et al. 2003) was then added to the flask, causing the sporangia to release zoospores into the DS. The flask was ready for use the next day.

Zoospore counts were made immediately before inoculation to estimate $B d$ concentration in the culture. We placed $0.5 \mathrm{ml}$ of the DS/zoospore solution in a $2 \mathrm{ml}$ micro-centrifuge tube and chilled it for a few min at $-20^{\circ} \mathrm{C}$, to slow zoospore activity before counting. Once cooled, the solution was shaken gently and a small volume was pipetted onto the 2 counting chambers of a hemocytometer. Depending on zoospore density, we made between 3 and 10 counts within $1 \mathrm{~mm}^{2}$ sections. The mean count per square mm was multiplied by $10^{4}$ to estimate zoospore concentration per ml.

At 2-wk intervals after the first inoculation, all surviving tadpoles were measured (body length, to the nearest $0.1 \mathrm{~mm}$ ) and staged (Gosner 1960). Then their mouthparts were swabbed using rounded, wooden toothpicks with sharply pointed ends. A new, clean toothpick was used for each tadpole. Five 'swabbers' 


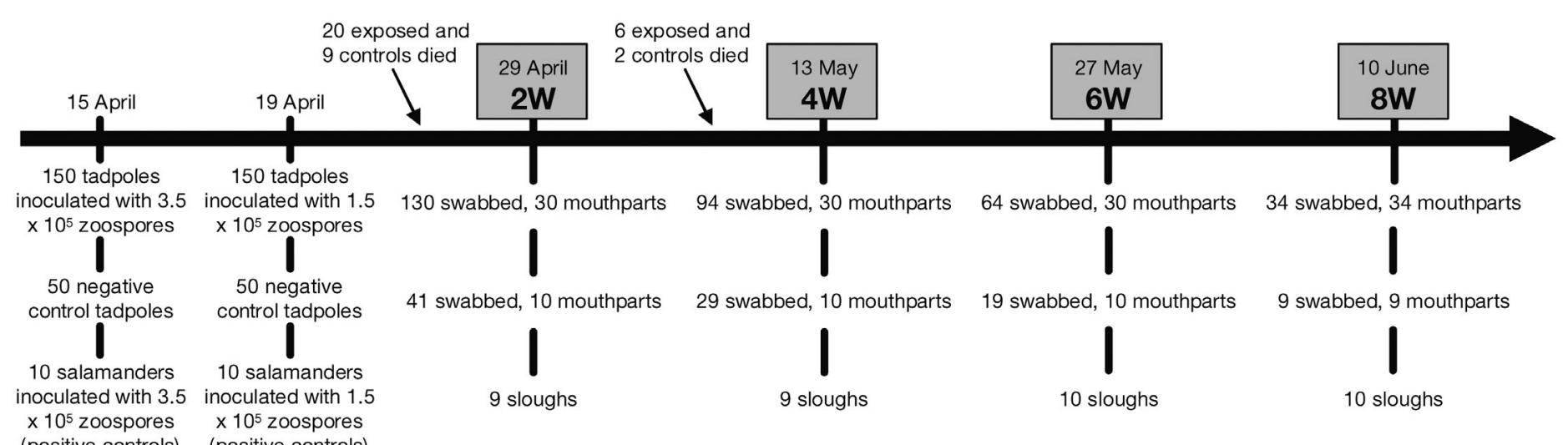

Fig. 1. Rana subaquavocalis. Outline of the experiment, showing numbers of animals inoculated with Batrachochytrium dendrobatidis $(B d)$, numbers that died, and samples collected during each 2-wk interval (2W: 2 wk after the first inoculation; $4 \mathrm{~W}: 4$ wk after the first inoculation; etc.). Mouthparts: mouthpart excision. No salamander died during the experiment, but sloughed skin was not obtained from every salamander at $2 \mathrm{~W}$ and $4 \mathrm{~W}$

sampled tadpoles, with no more than 3 people swabbing at any session. The points of the toothpicks were scraped and rolled over and between the tooth rows and the keratinized beak of the tadpoles. Broken pieces of labial teeth were usually visible on the toothpick after swabbing. Swabs were stored in $70 \%$ ethyl alcohol (EtOH) in $2 \mathrm{ml}$ screw-cap microcentrifuge tubes (VWR, No. 16466-060), and tadpoles were placed back in their containers. At each 2-wk interval, after all tadpoles were swapped, 30 exposed and 10 control tadpoles were killed using MS-222, and their mouthparts were excised and screened for $B d$ as a complementary test. Mouthparts and carcasses were then preserved separately in $70 \% \mathrm{EtOH}$ in $2 \mathrm{ml}$ screw-cap microcentrifuge tubes. The design called for a total of 150 corresponding pairs of swabs and mouthparts, collected in groups of 30 at 2 -wk intervals, along with multiple swabs collected at 2-wk intervals from most individuals (i.e. 2 swabs from 120 tadpoles, 3 swabs from 90 tadpoles, 4 swabs from 60 tadpoles, and 5 swabs from 30 tadpoles). Tadpoles died during the course of the experiment so actual numbers deviated from the original design (Fig. 1). Sloughed skin was collected from each salamander at 2 -wk intervals as a positive control.

$B d$ DNA was extracted from samples following the PrepMan Ultra protocol (www.appliedbiosystems. com), with slight modifications to allow for various tissue types and volumes. Our final protocols were as follows:

Swabs. Microcentrifuge tubes containing swabs were centrifuged at $13000 \mathrm{rpm}(18000 \times g)$ for $10 \mathrm{~min}$. The ethanol was then removed using a clean pipette for each tube, taking particular care not to dislodge or remove centrifuged pellets. Swabs were then re-suspended in $1 \mathrm{ml} 1 \times$ TE buffer $(10 \times$ TE buffer: $100 \mathrm{mM}$ Tris, 10 mM EDTA (pH 8); diluted to $1 \times$ by adding ster- ile water), which helped to remove remaining ethanol from the sample, but did not jeopardize the integrity of the DNA, which was still within intact cells. Swabs were soaked overnight in the buffer, and the tubes were then centrifuged for $10 \mathrm{~min}$ more at $13000 \mathrm{rpm}$. As much of the TE buffer as possible was then removed using a clean pipette for each tube, again taking particular care not to dislodge or remove centrifuged pellets. All tubes were agitated in a vortex for 2 min after adding $40 \mu$ of Prepman Ultra (Applied Biosystems) to each tube. The preparations were boiled within their tubes for $10 \mathrm{~min}$ at $100^{\circ} \mathrm{C}$, and then cooled for 2 min before they were again centrifuged at $13000 \mathrm{rpm}$ for $3 \mathrm{~min}$. A total of $20 \mu \mathrm{l}$ of the supernatant was removed from each tube and placed into a new, clean $2 \mathrm{ml}$ microcentrifuge tube, and then $180 \mu \mathrm{l}$ of water were added to produce a $1 / 10$ dilution.

Mouthparts and sloughed skin. Tissue samples were removed from their microcentrifuge tubes using clean toothpicks and placed into new tubes with $1 \mathrm{ml}$ of $1 \times$ TE buffer and left overnight. Using new toothpicks, samples were then removed from the buffer and placed into a third new tube containing $200 \mu$ l PrepMan Ultra and a small scoop (30 to $40 \mathrm{mg}$ ) of zirconium/silica beads (diam. $=0.5 \mathrm{~mm}$; BioSpec Products). Using a FastPrep machine (Qbiogene), samples were then mechanically homogenized twice in their tubes, each time for $45 \mathrm{~s}$ at setting 6.5 . The preparations were boiled within their tubes for $10 \mathrm{~min}$ at $100^{\circ} \mathrm{C}$, and then cooled for $2 \mathrm{~min}$ before they were again centrifuged at $13000 \mathrm{rpm}$ for $3 \mathrm{~min}$. A total of $20 \mu \mathrm{l}$ of the supernatant was removed from each tube and placed into a new, clean tube. Then, $180 \mu \mathrm{l}$ of water were added to produce a 1/10 dilution.

The final swab and tissue preparations were stored at $-20^{\circ} \mathrm{C}$ until they were used for quantitative PCR 
(qPCR). qPCR was run on every sample in 384-well plates (Applied Biosystems, No. 4309849) in an Applied Biosystems Sequence Detection System 7900HT following Boyle et al. (2004), but using $125 \mathrm{nM}$ of the minor groove binder (MGB) probe rather than $250 \mathrm{nM}$. The PCR procedure was repeated for samples that produced uncertain results. For each positive qPCR sample, we assigned a level of infection (range of values $=1$ to 5 ) based on the quantified strength of that

Table 1. Rana subaquavocalis. Number of exposed tadpoles (no controls) killed at each 2-wk interval (for definition of sessions, see Fig. 1) that were found to be infected with $B d$ using lethal sampling (mouthpart excision) and swabbing

\begin{tabular}{|c|c|c|c|c|c|}
\hline $\mathrm{n}:$ & $\begin{array}{c}2 \mathrm{~W} \\
30\end{array}$ & $\begin{array}{l}4 \mathrm{~W} \\
30\end{array}$ & $\begin{array}{c}6 \mathrm{~W} \\
30\end{array}$ & $\begin{array}{l}8 W \\
34\end{array}$ & $\begin{array}{c}\text { Overall } \\
124\end{array}$ \\
\hline \multicolumn{6}{|c|}{ Mouthpart excision } \\
\hline No. infected & 12 & 9 & 13 & 17 & 51 \\
\hline$\%$ & 40.0 & 30.0 & 43.3 & 50.0 & 41.1 \\
\hline \multicolumn{6}{|l|}{ Swabbing } \\
\hline No. infected & 2 & 6 & 8 & 15 & 31 \\
\hline$\%$ & 6.7 & 20.0 & 26.7 & 44.0 & 25.0 \\
\hline
\end{tabular}

sample relative to known positive standards (Boyle et al. 2004).

To prevent contamination, we consistently cleaned, disinfected with bleach, and dried all containers used to hold tadpoles or salamanders before re-use, and used disposable latex gloves, 1 pair per animal, to capture and handle tadpoles and salamanders and to handle samples in the preparation for PCR.

Data were analyzed using various tests, as indicated in the 'Results' section. All statistical analyses were performed using SYSTAT 10.2.01.

\section{RESULTS}

\section{Tadpole mortality}

Between 0 and 2 wk, 29 Rana subaquavocalis tadpoles died (20 exposed and 9 controls); 8 more died (6 exposed and 2 controls) between 2 and 4 wk (Fig. 1). No salamanders died during the experiment. We suspect that bacterial or chemical pollutants in the water or food, rather than injury from swabbing, caused some tadpoles to die. None died after the fourth week, which suggests the husbandry issue was corrected by then. Enough tadpoles died to make the fifth scheduled swabbing session (10W, 10 wk after first inoculation) pointless. After the fourth (8W) swabbing session, no control tadpoles and only 4 exposed tadpoles remained, so those 4 tadpoles were killed and assessed with the $8 \mathrm{~W}$ tadpoles, concluding the experiment.

\section{$B d$ infection}

All salamander controls were positive for $B d$ throughout the experiment, indicating that the pathogen strain could successfully infect an amphibian

Table 3. Rana subaquavocalis. Correspondence between estimates of infection with $B d$ using lethal sampling (excised mouthparts) and swabbing for exposed tadpoles (no controls) killed at each session. These data do not include tadpoles that died between $2 \mathrm{~W}$ and $4 \mathrm{~W}$ (for session details, see Fig. 1)

\begin{tabular}{|c|c|c|c|c|c|c|c|c|c|c|c|c|}
\hline & & \multirow[b]{2}{*}{$\mathrm{n}:$} & & & & & $\operatorname{sed} n$ & hpart & & & \multicolumn{2}{|c|}{ Overall } \\
\hline & & & $\begin{array}{c}2 \mathrm{~W} \\
12\end{array}$ & $\begin{array}{c}4 \mathrm{~W} \\
9\end{array}$ & $\begin{array}{c}6 \mathrm{~W} \\
13\end{array}$ & $\begin{array}{c}8 \mathrm{~W} \\
17\end{array}$ & $\begin{array}{c}2 W \\
18\end{array}$ & $\begin{array}{c}4 \mathrm{~W} \\
21\end{array}$ & $\begin{array}{c}6 \mathrm{~W} \\
17\end{array}$ & $\begin{array}{c}8 \mathrm{~W} \\
17\end{array}$ & $\begin{array}{c}B d+ \\
51\end{array}$ & $\begin{array}{c}B d- \\
73\end{array}$ \\
\hline \multirow[t]{2}{*}{ Swabs } & $B d+$ & & $\begin{array}{c}2 \\
(17 \%)\end{array}$ & $\begin{array}{c}6 \\
(67 \%)\end{array}$ & $\begin{array}{c}8 \\
(62 \%)\end{array}$ & $\begin{array}{c}15 \\
(88 \%)\end{array}$ & 0 & 0 & $\begin{array}{c}1 \\
(6 \%)\end{array}$ & $\begin{array}{c}1 \\
(6 \%)\end{array}$ & $\begin{array}{c}31 \\
(61 \%)\end{array}$ & $\begin{array}{c}2 \\
(3 \%)\end{array}$ \\
\hline & $B d-$ & & 10 & 3 & 5 & 2 & 18 & 21 & 16 & 16 & 20 & 71 \\
\hline
\end{tabular}


and persist. Among tadpoles, consistently higher prevalence of $B d$ was detected by lethal sampling than by swabbing (Table 1). The prevalence among killed tadpoles was $41.1 \%$ overall, varied from 30 to $50 \%$ among sessions (Table 1), and did not vary significantly with time (Pearson chi-squared test: $\chi^{2}=2.716$, $\mathrm{df}=3, \mathrm{p}=0.438$ ).

Tadpoles diagnosed with infection by swabbing or lethal sampling yielded 147 swabs, of which 73 (50\%) were infected. This includes repeated swabs of some tadpoles at different swabbing sessions. $B d$ was detected on at least 1 swab from 38 individuals in the experiment (Table 2).

$B d$ was detected on at least 1 swab from most tadpoles whose mouthparts were infected experimentally, and not detected on any but 1 of the swabs from uninfected tadpoles. Eighteen tadpoles whose mouthparts were infected never yielded infected swabs. Two exposed tadpoles yielded infected swabs, but uninfected mouthparts (Table 3), perhaps indicating that tadpoles can clear infection naturally, or that infection was extremely localized and light on some tadpoles and removed entirely by the swabs, or that some samples became contaminated. One infected swab was obtained from a control tadpole at $4 \mathrm{~W}$, which suggests some contamination.

$B d$ was detected on swabs in every 2-wk session. First session (2W) levels were lowest $(6.7 \%)$, while levels in the final session (8W) were highest $(44.0 \%)$ (Table 1). There was a significant increase in the likelihood of $B d$ detection by swabbing as the experiment progressed (Pearson chi-squared test: $\chi^{2}=19.00, \mathrm{df}=3$, $\mathrm{p}<0.001)$.

$B d$ was not detected on every swab from every infected tadpole, but multiple swabs of infected individuals increased the likelihood of detecting $B d$. Infection was detected on only $14 \%$ of tadpoles swabbed once (Table 2). For tadpoles swabbed 2 or 3 times, 20 and $30 \%$ of individuals, respectively, were found to be infected; $6.7 \%$ of tadpoles in each of these 2 categories had positive swabs every time. Infection was detected
Table 4. Rana subaquavocalis. Bd detection rates for each sampler at each session for tadpoles that were found to be infected (i.e. no controls or uninfected tadpoles included). Infection status of tadpoles was determined by any swab and/or by lethal sampling. These data include infected tadpoles that were swabbed at $2 \mathrm{~W}$ (for session details, see Fig. 1), but died before $4 \mathrm{~W}$

\begin{tabular}{|lccrc|}
\hline Session & Sampler & $\begin{array}{c}\text { No. of swabs } \\
\text { from infected } \\
\text { individuals }\end{array}$ & $\begin{array}{c}B d+ \\
\text { swabs }\end{array}$ & $\begin{array}{c}\text { Detection } \\
\text { rate } \\
(\%)\end{array}$ \\
\hline 2W & A & 17 & 2 & 11.7 \\
& B & 25 & 12 & 48.0 \\
& C & 15 & 4 & 26.7 \\
4W & A & 14 & 11 & 78.6 \\
& D & 18 & 8 & 44.4 \\
$6 \mathrm{~W}$ & E & 9 & 2 & 22.2 \\
& A & 12 & 6 & 50.0 \\
8W & B & 20 & 17 & 85.0 \\
Mean & A & 10 & 9 & 90.0 \\
& B & 7 & 6 & 85.7 \\
& - & 14.7 & 7.7 & 54.2 \\
\hline
\end{tabular}

on $53 \%$ of tadpoles swabbed 4 times, but only $8.8 \%$ of tadpoles had positive swabs all 4 times.

$B d$ detection rates varied among samplers from 11.7 to $90.0 \%$ (mean $=54.2 \%$ ) (Table 4$)$. Given the mean detection rate, there was approximately a 1-in-2 chance of the average swabber detecting $B d$ when sampling an infected tadpole. Samplers who participated in $>1$ session became more likely to detect $B d$, perhaps due to improving their technique or an increase in the tadpoles' infection levels, or both.

\section{Bd infection and tadpole size and development}

There were no significant differences between the sizes or developmental stages of treatment groups at the start of the experiment. Tadpoles in control and exposed groups were similar in size (2-sample $t$-test: $t=-1.150, \mathrm{df}=161, \mathrm{p}=0.252)$ and developmental

Table 5. Rana subaquavocalis. Initial sizes (body length, BL) and developmental stages of tadpoles (Gosner 1960) at the commencement of the experiment (all measurements made at $2 W_{;}$for session details, see Fig. 1). Tadpoles are grouped by the 2 -wk sessions in which they were later sacrificed

\begin{tabular}{|c|c|c|c|c|c|c|c|c|c|c|}
\hline \multirow{3}{*}{$\begin{array}{l}\text { Sacrified in } \\
\text { session }\end{array}$} & \multirow[t]{3}{*}{$\mathrm{n}$} & \multicolumn{4}{|c|}{ Exposed to $B d-$} & \multirow[t]{3}{*}{$\mathrm{n}$} & \multicolumn{4}{|c|}{ - Controls } \\
\hline & & \multicolumn{2}{|c|}{ BL (mm) } & \multicolumn{2}{|c|}{ Stage } & & \multicolumn{2}{|c|}{$\mathrm{BL}(\mathrm{mm})$} & \multicolumn{2}{|c|}{ Stage } \\
\hline & & Mean & SD & Mean & $\mathrm{SD}$ & & Mean & $\mathrm{SD}$ & Mean & SD \\
\hline $2 \mathrm{~W}$ & 30 & 16.27 & 1.51 & 26.07 & 1.80 & 10 & 15.55 & 1.36 & 25.70 & 0.95 \\
\hline $4 \mathrm{~W}$ & 30 & 15.56 & 1.40 & 25.67 & 1.18 & 10 & 15.25 & 0.90 & 25.10 & 0.32 \\
\hline $6 \mathrm{~W}$ & 30 & 15.76 & 1.62 & 25.73 & 1.17 & 10 & 15.52 & 1.94 & 25.70 & 1.25 \\
\hline $8 \mathrm{~W}$ & 34 & 15.56 & 1.45 & 25.68 & 1.20 & 9 & 15.57 & 1.19 & 25.22 & 0.44 \\
\hline All animals & 124 & 15.78 & 1.51 & 25.78 & 1.35 & 39 & 15.47 & 1.36 & 25.44 & 0.85 \\
\hline
\end{tabular}


Table 6. Rana subaquavocalis. Results of ANCOVA for the relationships between tadpole size and development and the likelihood of detecting $B d$ by swabbing

\begin{tabular}{|lrrrrr|}
\hline $\begin{array}{l}\text { Source of } \\
\text { variation }\end{array}$ & $\begin{array}{c}\text { Sum of } \\
\text { squares }\end{array}$ & $\begin{array}{c}\text { Mean } \\
\text { square }\end{array}$ & F-ratio & df & $\mathrm{p}$ \\
\hline Size & & & & & \\
$\begin{array}{l}\text { Swab result } \\
\text { Session }\end{array}$ & 0.420 & 0.420 & 0.212 & 1 & 0.646 \\
$\begin{array}{l}\text { Error } \\
\text { Development }\end{array}$ & 287.963 & 278.963 & 140.453 & 1 & $<0.001$ \\
$\begin{array}{l}\text { Swab result } \\
\text { Session }\end{array}$ & 0.126 & 0.126 & 0.036 & 1 & 0.850 \\
Error & 1395.960 & 1395.960 & 394.007 & 1 & $<0.001$ \\
& 513.732 & 3.543 & & 145 & \\
\hline
\end{tabular}

parts increased with time on individuals swabbed repeatedly (swabs: ANOVA, F-ratio $=9.138, \mathrm{df}=3, \mathrm{p}<0.001 ;$ mouthparts: ANOVA, $F$-ratio $=6.200$, df $=3, p=0.001$, Fig. 3).

\section{Swabbing versus lethal sampling - How many tadpoles are needed?}

Inoculation with $B d$ infected $41.1 \%$ of tadpoles whose mouthparts were excised and analyzed using $\mathrm{qPCR}_{\text {; }}$ this is our best estimate of prevalence in our tadpole 'population'. Estimates of $\mathrm{Bd}$ infection using swabs stage $t$-test: $t=-1.506, \mathrm{df}=161, \mathrm{p}=0.134)$, as were tadpoles in all groups that were later sampled lethally at different 2-wk intervals (variation in size: ANOVA, Fratio $=1.344$, $\mathrm{df}=3,159, \mathrm{p}=0.262$; variation in developmental stage: ANOVA, $F$-ratio $=1.029, \mathrm{df}=3,159$, $\mathrm{p}=0.382$ ) (Table 5).

Of the 150 exposed tadpoles, 130 survived to be swabbed and 57 of those became infected. Infected tadpoles were significantly smaller at the start of the experiment (body lengths at 2W) than uninfected tadpoles ( $t$-test: $t=2.986, \mathrm{df}=128, \mathrm{p}=0.003$ ), but similar developmentally ( $t$-test: $t=0.744, \mathrm{df}=128, \mathrm{p}=0.459$ ).

We used $t$-tests to compare the size and development of infected tadpoles for which infected swabs were obtained with the size and development of infected tadpoles for which no infected swabs were obtained. This analysis showed that $B d$ was detected significantly more from swabs of larger $(t=-3.005, \mathrm{df}=$ 146, $\mathrm{p}=0.003$ ) and more-advanced tadpoles $(t=-3.988$, df $=146, \mathrm{p}<$ 0.001). However, further exploration of those data using ANCOVA, with sampling session as the covariate, showed that patterns with both attributes were explained by between-session rather than within-session variation, and that the likelihood of detecting infection at any one time was not related to tadpole size or development (Table 6). Because relatively few infected samples were detected during the early sessions when tadpoles were small, and more were detected during the later sessions when tadpoles were large (Fig. 2), 'positive' tadpoles were larger and more developed on average than 'negative' tadpoles.

Estimated levels of infection detected by swabbing or excising mouth- varied from $4.8 \%(11.7 \%$ of $41.1 \%)$ to $37.0 \%(90.0 \%$ of $41.1 \%$ ) (mean $=22.2 \%$ [54.2\% of $41.1 \%$ ]) of samples, depending on sampler and date (Table 4).

Following Martin et al. (1987, after Cannon \& Roe

$$
n=\left[1-(1-\alpha)^{1 / D}\right][N-(D-1) / 2]
$$

(where $n$ is the required sample size, $\alpha$ is the probability of observing at least 1 infected tadpole in the sample when $B d$ infects at least $D / N$ in the population, $D$ is the number of infected tadpoles in the population, and $N$ is the population size) to estimate the sample sizes needed to be statistically confident that $B d$ prevalence detected by swabbing was at or below the level detected by excising the mouthparts of experimental animals (Table 7). Hypothetical Bd prevalence is also used to estimate sample sizes needed for tadpole populations with other characteristics (Table 7). 1982) we used:

Table 7. Rana subaquavocalis. Number of negative samples required (rounded up to the nearest whole animal), assuming no $B d$ is found, to be $95 \%$ confident that $B d$ is absent or below the expected prevalence $(41.1 \%$ in the present study; other hypothetical prevalence presented), if lethal (excision of mouthparts) versus non-lethal (swabbing) sampling methods are used for populations of 100 or 1000 tadpoles. Lethal sampling assumes $100 \%$ detection rate. Swabbing detection rates encompass those found in the present study

\begin{tabular}{|lcrrrr|}
\hline $\begin{array}{l}\text { Population } \\
\text { size }\end{array}$ & $\begin{array}{c}\text { Expected } \\
\text { prevalence } \\
(\%)\end{array}$ & $\begin{array}{c}\text { No. samples required by } \\
\text {... lethal } \\
\text { sampling }\end{array}$ & $\begin{array}{c}\text { High } \\
\text { High } \\
(90.0 \%)\end{array}$ & $\begin{array}{c}\text { Average } \\
(54.2 \%)\end{array}$ & $\begin{array}{c}\text { Low } \\
(11.7 \%)\end{array}$ \\
\hline 100 & 41.1 & 6 & 9 & 12 & 46 \\
& 20 & 13 & 15 & 23 & 72 \\
& 10 & 25 & 28 & 42 & 93 \\
& 5 & 45 & 48 & 67 & 100 \\
1000 & 95 & 97 & 100 & 100 \\
& 41 & 6 & 7 & 12 & 59 \\
& 14 & 16 & 26 & 119 \\
& 10 & 29 & 32 & 53 & 225 \\
& 5 & 57 & 63 & 103 & 400 \\
& 1 & 258 & 282 & 424 & 923 \\
\hline
\end{tabular}



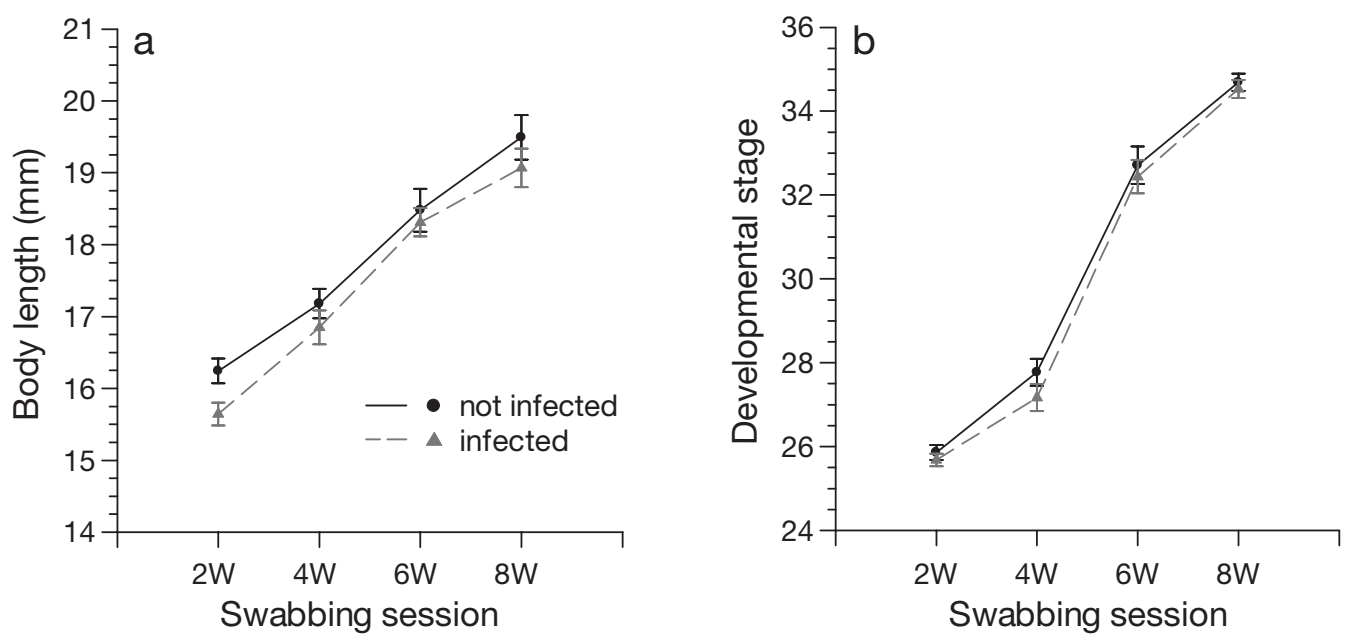

Fig. 2. Rana subaquavocalis. (a) Body lengths and (b) developmental stages during the experiment for exposed tadpoles that became infected or remained uninfected after inoculation (no controls). Data presented are means $( \pm \mathrm{SE})$. Infection status of tadpoles was determined by any swab and/or by lethal sampling. For both graphs $\mathrm{n}=130,94,64,34$, respectively, for $2 \mathrm{~W}$, 4W, $6 \mathrm{~W}$, and $8 \mathrm{~W}$ sessions (for session details, see Fig. 1)
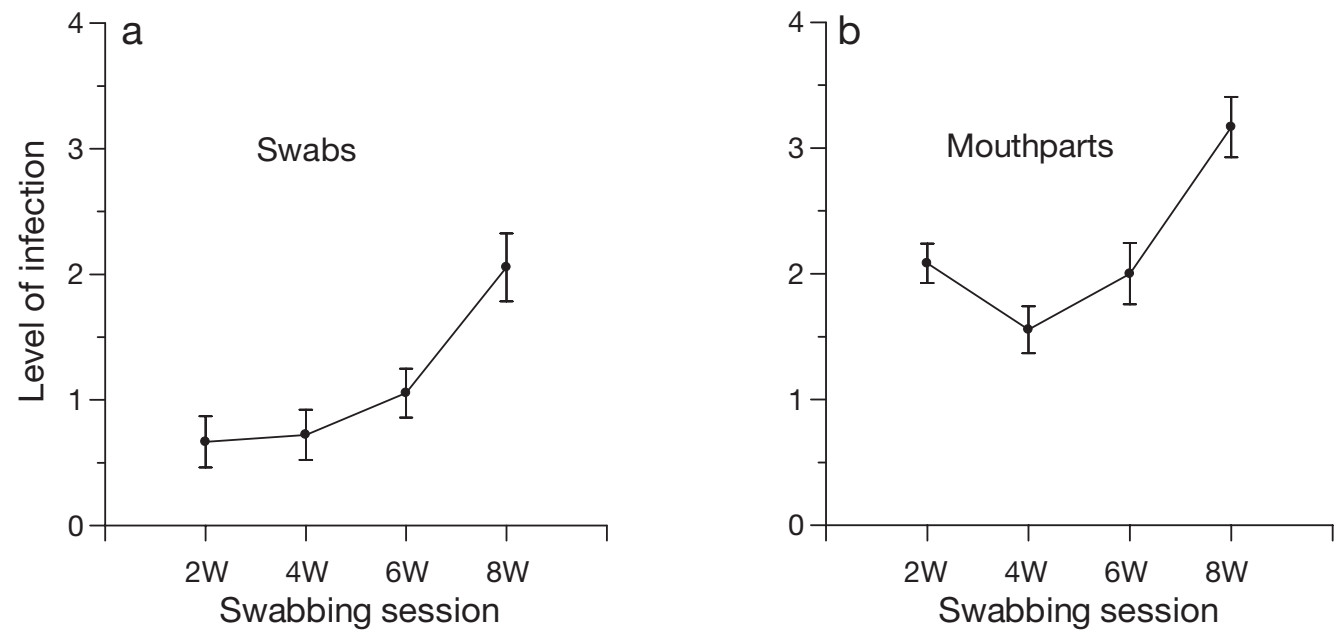

Fig. 3. Rana subaquavocalis. Qualitative levels of infection (mean \pm SE) at each session (a) from swabs of 18 infected tadpoles that were sampled 4 times and then killed at $8 \mathrm{~W}$ and (b) for mouthparts of infected tadpoles killed at different sessions $(\mathrm{n}=12,9,13$, and 17, respectively, for sessions). For level of infection, $0=$ not detected, $1=$ lightest detected infection, and $5=$ heaviest detected infection. For 1 tadpole killed at 8W, the mouthparts were not infected, but a swab from an earlier session was; that tadpole is included in (a), but not at $8 \mathrm{~W}$ in (b)

\section{DISCUSSION}

Swabbing the mouthparts of tadpoles is an effective technique for $B d$ diagnosis that complements visual surveys (Rachowicz \& Vredenburg 2004) or lethal techniques, but it has limitations.

Swabbing never equaled or surpassed the detection rate from lethal diagnosis at any point, so the latter appears to be a more sensitive technique. However, detecting $B d$ by swabbing improved greatly after the first 2-wk (2W) session, and we observed up to $90 \%$ correspondence between swabbing and lethal diagnosis by the $8 \mathrm{~W}$ session. There are several possible causes: (1) Each swabber's technique likely improved during the study. Pressure applied by different swabbers to the toothpick on the mouthparts probably varied while swabbing. Swabbers became more uniform and effective in their technique following discussion about methods after each session. We recommend sampling by the same swabber each time for consistent comparisons among multiple $B d$ surveys. (2) $B d$ infection on individual tadpoles likely increased throughout the experiment, improving the pathogen's detectability by swabbing. (3) Abrading tissue by swabbing may allow infection to develop or cause labial teeth to become more brittle and therefore easier to swab. 
(4) Later in the experiment tadpoles were easier to handle and swab because they were larger and had larger mouthparts. Although prevalence estimated by swabbing did not depend on tadpole size, it is still possible that larger tadpoles are easier to swab than smaller ones.

Rather than using expensive and specialized surgical cotton swabs as recommended by Hyatt (2004), we used wooden toothpicks, which are less expensive and more readily available. We have used toothpicks for swabbing post-metamorphic amphibians with good success for years (V. Miera \& R. W. R. Retallick unpubl. data). Some wood may interfere with PCR (Lee \& Cooper 1995), but our results show little sign of that. By the $8 \mathrm{~W}$ session, we observed $88 \%$ correspondence between infected mouthparts and swabs, which demonstrates that wood was effective for our application. Using the recommended surgical swabs may result in even closer correspondence. Wood is likely to be more abrasive than other materials such as cotton swabs and, depending on the skill of the swabber, may damage mouthparts and influence the ability of tadpoles to feed. Less abrasive swabs may lessen the risk of injury, but may not collect $B d$ DNA from tadpole mouthparts as effectively. We had no mortality that could be attributed to swabbing, but we did not follow individuals through their larval development.

Because $B d$ prevalence estimates vary with technique, we recommend calibrating estimates obtained by swabbing with estimates from a smaller sample of excised mouthparts. Because lethal diagnosis samples the entire mouth for $B d$, while swabbing may not, we assume that $B d$ prevalence estimated by lethal diagnosis is a more reliable estimate of the true population prevalence.

$B d$ was not detected on every swab from every infected tadpole. Some swabs from the same individual at subsequent sessions were infected then uninfected and vice versa. Various explanations may account for this: each sampler's technique varied to the point that $B d$ was or was not detected, infection loads fluctuated above and below detectable levels, or tadpoles cleared their infection. We found evidence suggesting that the increased likelihood of detecting $B d$ with multiple swabs (i.e. $B d$ was detected on $14 \%$ of infected individuals swabbed once, yet $53 \%$ of individuals swabbed 4 times) was attributable to an increase in $B d$ infection levels on individual tadpoles over time.

While the level of $B d$ infection increased over time, prevalence did not. If this pattern is consistent among tadpoles when $B d$ first enters a population, that suggests swabbing would be most suitable when applied to tadpoles that have long larval durations. If tadpoles have been exposed to $B d$ in the waterbody for only a short period before the swabbing is performed, then infection level, and therefore detection rate by swabbing, may be low.

We conclude that swabbing is a useful technique for $B d$ detection in tadpoles, particularly in populations where frogs are absent or difficult to capture. The applicability of the technique will likely vary among species and with mean prevalence in the population. When the ability to detect $B d$ is moderate to high (Table 7), swabbing mouthparts is a practical method for non-lethally sampling tadpoles to estimate $B d$ prevalence.

Acknowledgements. Arizona Game and Fish Department, US Fish and Wildlife Service, ASU, and NSF provided financial and logistical support. This research was completed under the ASU Institutional Animal Care and Use Committee (IACUC) Protocol No. 03-670R. We thank T. Beatty Sr. of Beatty's Guest Ranch in Miller Canyon, Arizona, for access to the field site, J. E. Longcore (University of Maine) for broth culture recipes, and 4 anonymous reviewers for comments that improved the manuscript.

\section{LITERATURE CITED}

Berger L, Speare R, Daszak P, Green DE and 10 others (1998) Chytridiomycosis causes amphibian mortality associated with population declines in the rain forests of Australia and Central America. Proc Natl Acad Sci USA 95: 9031-9036

Berger L, Speare R, Kent A (1999) Diagnosis of chytridiomycosis in amphibians by histologic examination. Available at www.jcu.edu.au/school/phtm/PHTM/frogs/ histo/chhisto.htm

Berger L, Marantelli G, Skerratt LF, Speare R (2005) Virulence of the amphibian chytrid fungus Batrachochytrium dendrobatidis varies with the strain. Dis Aquat Org 68: 47-50

Boyle DG, Hyatt AD, Daszak P, Berger L, Longcore JE, Porter D, Hengstberger SG, Olsen V (2003) Cryoarchiving of Batrachochytrium dendrobatidis and other chytridiomycetes. Dis Aquat Org 56:59-64

Boyle DG, Boyle DB, Olsen V, Morgan JAT, Hyatt AD (2004) Rapid quantitative detection of chytridiomycosis (Batrachochytrium dendrobatidis) in amphibian samples using real-time Taqman PCR assay. Dis Aquat Org 60: 141-148

Briggs C, Vredenberg V (2004) Swab protocol (2004-2007) (Briggs, UC Berkeley). Available at http://amphibiaweb. org/chytrid/swab_instruction.pdf

Brunner JL, Schock DM, Collins JP, Davidson EW (2004) The role of an intraspecific reservoir in the persistence of a lethal ranavirus. Ecology 85:560-566

Cannon RM, Roe RT (1982) Livestock disease surveys: a field manual for veterinarians. Australian Government Publishing Service, Canberra

Gosner KL (1960) A simplified table for staging anuran embryos and larvae with notes on identification. Herpetologica 16:183-190

Hyatt AD (2004) Diagnostic assays and sampling protocols for the detection of Batrachochytrium dendrobatidis $(B d)$ 
(CSIRO, Australia). Available at www.jcu.edu.au/school/ phtm/PHTM/frogs/protocols/bd-swab-protocol.pdf

Knapp RA, Morgan JAT (2006) Tadpole mouthpart depigmentation as an accurate indicator of chytridiomycosis, an emerging disease of amphibians. Copeia 2006:188-197

Kriger KM, Hines HB, Hyatt AD, Boyle DG, Hero JM (2006) Techniques for detecting chytridiomycosis in wild frogs: comparing histology with real-time Taqman PCR. Dis Aquat Org 71:141-148

Lee AB, Cooper TA (1995) Improved direct PCR screen for bacterial colonies - wooden toothpicks inhibit PCR amplification. Biotechniques 18(2):225-226

Livo LJ (2004) Methods for obtaining Batrachochytrium dendrobatidis $(B d)$ samples for PCR testing. Available at http://wildlife.state.co.us/NR/rdonlyres/710BBC95-2D CF-4CF9-8443-D4561DBC3B69/0/PCRsampling2004.pdf

Editorial responsibility: Otto Kinne, Oldendorf/Luhe, Germany
Marantelli G, Berger L, Speare R, Keegan L (2004) Distribution of the amphibian chytrid Batrachochytrium dendrobatidis and keratin during tadpole development. Pac Conserv Biol 10(1):173-179

Martin SW, Meek AH, Willeberg P (1987) Veterinary epidemiology, principles and methods. Iowa State University Press, Ames, p 35-38

Rachowicz LJ, Vredenburg VT (2004) Transmission of Batrachochytrium dendrobatidis within and between amphibian life stages. Dis Aquat Org 61:75-83

Speare R (2005) Articles on Batrachochytrium dendrobatidis: the amphibian chytrid. Available at www.jcu.edu.au/ school/phtm/PHTM/frogs/chart.htm

Stuart SN, Chanson JS, Cox NA, Young BE, Rodrigues ASL, Fischman DL, Waller RW (2004) Status and trends of amphibian declines and extinctions worldwide. Science 306:1783-1786

Submitted: September 12, 2005; Accepted: April 27, 2006

Proofs received from author(s): August 24, 2006 